\title{
Desarrollo del proceso de ozonización en la planta de tratamiento de agua envasada de la Empresa Pública Empresa Municipal de Agua Potable y Alcantarillado de Ambato (EP-EMAPA-A).
}

Development of the ozonation process in the bottled water treatment plant of the Public Company Municipal Water and Sewage Company of Ambato (EPEMAPA-A).

Manolo Alexander Córdova Suárez. ${ }^{1}$, Jonathan Vinicio Gavilanes López. ${ }^{2}$, Oscar Eduardo Ruíz Robalino. ${ }^{3}$ \& José Geovanny Vega Pérez. ${ }^{4}$

Recibido: 13-09-2017 / Revisado: 07-11-2017 Aceptado: 05-12-2018/ Publicado: 01-01-2018

\begin{abstract}
.
DOI: https://doi.org/10.33262/cienciadigital.v2i3.167

The use of Ozone $\left(\mathrm{O}_{3}\right)$ as part of the water treatment process is more common for its bactericidal and virulitic power and also for the ability to remove large amounts of undesirable organic or mineral substances (Kolosov et al., 2018). Due to its high solubility, reliable generation and its robust reactive properties (Wei et al., 2017) ozonation became a viable technique for the treatment of bottled water. The Laboratory of Production Control of the Water Packer in the Tilulúm Treatment Plant of the EPEMAPA-A, through this study, demonstrated that the application of Ozone in the process of disinfection for bottled water meets the required expectations at an industrial level, obtaining experimental data from the characteristic tests of the process, involving chemical, microbiological and statistical parameters that allowed to verify that the disinfection based on this gas $\left(\mathrm{O}_{3}\right)$ is appropriate for its purpose.
\end{abstract}

1 G+ Energy-Risks \& Engineering Group, Department of Food Science and Engineering, Technical University of Ambato, Ambato-Ecuador, ma.cordova@uta.edu.ec

2 G+ Energy-Risks \& Engineering Group, Department of Food Science and Engineering, Technical University of Ambato, Ambato-Ecuador, jonathangavilanes@hotmail.com

3 G+ Energy-Risks \& Engineering Group, Department of Food Science and Engineering, Technical University of Ambato, Ambato-Ecuador, oe.ruiz@uta.edu.ec, 4 G+ Energy-Risks \& Engineering Group, Department of Food Science and Engineering, Technical University of Ambato, Ambato-Ecuador, jg.vega@uta.edu.ec 
Methods: For the quantification of residual ozone (O3) for bottled water disinfection processes, the Indigo Method (Method HACH 8311) was used. Regarding the physicochemical, microbiological and sensorial analyzes, the tests of the Standard NTE INEN 2 200: 2008 for Packaged Water were used (See ANNEX B: Illustration B1 Standard NTE INEN 2 200: 2008). The Infostat Version 2016 and EXCEL ${ }^{\circledR}$ programs were used for the statistical analysis

Results: Was determined that the optimum dose of ozone in water to be packaged is 0.15 mgO3 / L (Dosing Scale: $1.75 \mathrm{~g} / \mathrm{h}$ ), maintaining a concentration of residual ozone equivalent to $0.08 \mathrm{mgO} \mathrm{R} / \mathrm{L}$ and $0,07 \mathrm{mg} / \mathrm{L}$ as ozone demand required to disinfect water. These established concentrations are supported by previous physicochemical, microbiological and sensorial analyzes carried out to verify the quality and guarantee of the water that will be provided to the Ambateña community as an additional service by the EP-EMAPA-A

Conclusion: The ozonation process in EP-EMAPA-A benefits in compliance with the ranges established in the NTE INEN 2 200: 2008 standard, in addition to a sensory analysis that sets a precedent in terms of acceptability by consumers.

Keywords: Ozone dosage, physicochemical analysis, microbiological analysis, sensory analysis

\section{Resumen.}

El uso de Ozono $\left(\mathrm{O}_{3}\right)$ como parte del proceso de tratamiento de agua es más habitual por su poder bactericida y virulicida y además por la capacidad de eliminar grandes cantidades de sustancias orgánicas o minerales no deseables (Kolosov et al., 2018). Por su alta solubilidad generación confiable y sus robustas propiedades reactivas (Wei et al., 2017) la ozonización se convierte en una técnica viable para el tratamiento de agua envasada. El Laboratorio de Control de Producción de la Envasadora de Agua en la Planta de Tratamiento Tilulúm de la EP-EMAPA-A, a través de este estudio se demostró que la aplicación de Ozono en el proceso de desinfección para agua envasada cumple con las expectativas requeridas a nivel industrial, obteniendo datos experimentales de los ensayos característicos del proceso, involucrando a parámetros químicos, microbiológicos y estadísticos que permitieron comprobar que la desinfección a base de este gas $\left(\mathrm{O}_{3}\right)$ es apropiado para su finalidad.

Métodos: Para la cuantificación de Ozono residual $\left(\mathrm{O}_{3}\right)$ para procesos de desinfección de agua envasada se empleó el Método Índigo (Método HACH 8311). En cuanto a los análisis fisicoquímicos, microbiológicos y sensoriales se utilizó los ensayos de la Norma 
NTE INEN 2 200:2008 para Agua Envasada (Ver ANEXO B: Ilustración B1 Norma NTE INEN 2 200:2008). Para el análisis estadístico se emplearon los programas Infostat Versión 2016 y EXCEL ${ }^{\circledR}$

Resultados: Se determinó que la dosis óptima de ozono en agua a ser envasada es de $0,15 \mathrm{mgO}_{3} / \mathrm{L}$ (Escala de Dosificación: 1,75 g/h), manteniéndose una concentración de ozono residual equivalente a $0,08 \mathrm{mgO}_{3} \mathrm{R} / \mathrm{L}$ y $0,07 \mathrm{mg} / \mathrm{L}$ como demanda de ozono requerida para desinfectar agua. Estas concentraciones establecidas se encuentran respaldadas mediante previos análisis fisicoquímicos, microbiológicos y sensoriales realizados para constatar la calidad y garantía del agua que será brindada a la comunidad ambateña como un servicio adicional por parte de la EP-EMAPA-A

Conclusión: El proceso de ozonización en la EP-EMAPA-A beneficia en el cumplimiento de los rangos establecidos en la norma NTE INEN 2 200:2008, además de un análisis sensorial que marca un precedente en cuanto a la aceptabilidad por parte de los consumidores.

Palabras Claves: Dosificación de Ozono, análisis fisicoquímicos, análisis microbiológicos, análisis sensoriales.

\section{Introducción .}

La Norma Técnica Ecuatoriana NTE INEN 2 200:2008 establece los requisitos que debe cumplir el Agua Purificada Envasada destinada para consumo humano (INEN, 2008). En la actualidad, Ecuador presenta altos índices de demanda para agua embotellada, por lo cual se exige un proceso riguroso y certero en la producción del líquido vital, dirigido principalmente a cumplir con los parámetros de calidad y eficiencia en beneficio de los consumidores. (De la Fuente, 2013)

El Ozono (O3) es un gas volátil presente de forma natural en la atmósfera, de color ligeramente azul y olor característico; es poco soluble en el agua y dependiendo de las características de la misma, se mantiene disuelto por apenas un par de minutos. Las dosis necesarias para desinfectar el líquido vital varían según la calidad del agua, así como la cantidad de ozono que se pierde por volatilización durante su aplicación. (Martínez, 2016)

Además, el ozono es el desinfectante de mayor eficiencia microbicida, requiriendo tiempos de contacto bastante cortos. Debido a su gran poder oxidante, el uso de ozono puede ser 
recomendable en el pretratamiento de agua, considerando un alto porcentaje en la reducción de metales disueltos y la remoción de materia orgánica. (Vargas, 2004)

Es por ello que hoy en día, la Ozonización se ha convertido en el método de mayor efectividad para la desinfección de agua y, resaltando su gran poder bactericida y virulicida, es el preferido por las Industrias de Agua Potable y Envasadoras de Agua a nivel mundial. (HIDRITEC, 2014)

\section{Materiales y método.}

\section{Cuantificación de Ozono Residual a través del Método Índigo (HACH 8311)}

\section{Preparación del Blanco}

Se colocaron $40 \mathrm{~mL}$ de agua destilada en un vaso de precipitación de $50 \mathrm{~mL}$. Posteriormente se utilizó una ampolla AccuVac del rango 0,00- 1,50 mg/L para O3R, y se sumergió a la misma dentro del agua destilada hasta que se llene y reaccione por completo con el reactivo de índigo. Se agitó al blanco durante 30 segundos y se limpió el exceso de agua de las paredes de la ampolla. Se utilizó el programa 456 para rango alto de ozono residual y en conjunto con el blanco preparado, se enceró el equipo (espectrofotómetro: $546 \mathrm{~nm}$ ).

\section{Medición de la Concentración de Ozono Residual en Muestras de Agua Envasada}

Se tomaron $40 \mathrm{~mL}$ de cada muestra de agua embotellada en un vaso de precipitación de 50 $\mathrm{mL}$ empleando una ampolla AccuVac del rango 0,00-1,50 mg/L para O3R, se sumergió a la misma dentro del agua ozonizada hasta que se llene y reaccione por completo con el reactivo de índigo. Se agitaron las muestras durante 30 segundos y se limpió el exceso de agua de las paredes de la ampolla. Se colocó en el espectrofotómetro previamente encerado considerando el programa 456 de $\mathrm{HACH}$ para rango alto de ozono residual y considerando una longitud de onda de $546 \mathrm{~nm}$. Se midieron las absorbancias que, por defecto del equipo y programa utilizado, generan resultados expresados en $\mathrm{mg} / \mathrm{L} \mathrm{O3}$.

\section{Análisis Microbiológico}

\section{Número Más Probable}

Para esta metodología se trabajó en conjunto con el equipo sellador QUANTI-TRAY SEALER, por lo que es necesario encenderlo desde el inicio, considerándose 30 minutos de calentamiento del equipo. Seguidamente, se colocaron $100 \mathrm{~mL}$ de las muestras de agua envasada en frascos esterilizados y previamente etiquetados. Se añadió el medio de cultivo IDEXX Colilert 250 a las muestras de agua. Se disolvió el medio y se colocaron dichas muestras en los posillos. Posteriormente, se sellaron las muestras cultivadas en el equipo 
Quanti-Tray Sealer y, finalmente, estas últimas fueron incubadas a $35^{\circ} \mathrm{C}$ durante $24 \mathrm{~h}$. conteo se realizó en función a las tablas de NMP para dispositivo Quanti-Tray.

\section{Placas 3M Petrifilm ${ }^{\text {TM }}$ para Recuento de Aerobios Mesófilos}

Se colocó la placa Petrifilm de 3M sobre una superficie nivelada. Se levantó la película del petrifilm y con la ayuda de una pipeta graduada, se inoculó $1 \mathrm{~mL}$ de las muestras de agua envasada. Con sumo cuidado se deslizó la película superior hacia abajo para que haga contacto con la muestra inoculada. Se colocó el esparcidor de muestra sobre la película encima del inóculo y cuidadosamente se lo presionó con el objetivo de distribuir la muestra por el área circular. Se retiró el esparcidor, levantándolo directamente de la placa. Finalmente se incubaron las muestras de petrifilm a $35^{\circ} \mathrm{C}$ durante $48 \mathrm{~h}$. Los recuentos se expresaron en unidades de NMP/100 mL para el caso de Coliformes Totales y Fecales y en UFC/mL para Aerobios Mesófilos.

\section{Parámetros establecidos en la Norma NTE INEN 2 200:2008 para Agua Envasada}

\section{Color}

Se llenó un tubo de Nessler de $50 \mathrm{~mL}$ con la muestra de agua a ser analizada y otro con agua destilada para realizar la comparación de este parámetro. Seguidamente, se retiró la tapa del lente del comparador de color y se prendió el equipo. Luego, se colocaron tanto el blanco (agua destilada) como la muestra de agua en sus lugares de análisis. Se procedió a efectuar la comparación con los patrones del disco de color que presentan una escala de 0-50 y de 5-100; considerando que la muestra es agua envasada se utilizó el disco de menor amplitud (0-50). La observación se realizó mirando verticalmente hacia abajo a través de los tubos, contra una superficie blanca, considerándose un ángulo tal que la luz se refleje hacia arriba a través de las columnas del líquido. Finalmente se registraron los datos observados.

\section{Turbiedad}

Se colocaron $10 \mathrm{~mL}$ de las muestras de agua envasada en las celdas de vidrios; se verificaron que estas últimas estén completamente limpias y finalmente se leyeron los datos registrados por el equipo en unidades nefelometricas de turbiedad (NTU).

\section{Solidos Totales Disueltos (STD)}

Se colocaron $100 \mathrm{~mL}$ de las muestras de agua envasada a analizar y se introdujo el bulbo del conductivimetro. Finalmente se registró la cantidad de STD equivalentes en unidades de $\mathrm{mg} / \mathrm{L}$.

\section{pH}


Se tomaron $100 \mathrm{~mL}$ de las muestras de agua envasadas. Se introdujo el bulbo del pHmetro y se esperó a que el equipo se estabilice. Finalmente se registró las lecturas proporcionadas.

\section{Cloro Libre}

Se colocaron $10 \mathrm{~mL}$ de las muestras de agua envasada en las celdas de vidrio. Posteriormente se añadió 4 gotas de DPD y se leyeron los datos registrados por el equipo en unidades de $\mathrm{mg} / \mathrm{L}$.

\section{Dureza}

Se midieron $50 \mathrm{~mL}$ de las muestras de agua envasada en diferentes erlenmeyer. Se añadió 1 $\mathrm{mL}$ de la solución de buffer y una punta de espátula de eriocromo. Se agitaron las muestras por 1 minuto y se titularon con EDTA hasta que la solución se volvió azul. Finalmente se registraron los resultados en unidades de $\mathrm{mg} / \mathrm{L}$.

\section{Sabor y Olor}

De acuerdo a lo estipulado en la Norma NTE INEN 2 200:2008 para Agua Envasada, marca como "INOBJETABLE" a estos parámetros, por lo que se decidió realizar un análisis sensorial del agua envasada a diferentes concentraciones de ozono.

\section{Evaluación Sensorial.}

Para juzgar las distintas concentraciones de ozono en agua envasada, se realizó un análisis sensorial considerando a 20 panelistas escogidos aleatoriamente. Además, se expuso en la hoja de cata, tres parámetros importantes a evaluar: Olor, Sabor y Aceptabilidad, de acuerdo a una escala hedónica marcada de 0 a 3.

\section{Diseño Experimental.}

La presente investigación comprendió dos secciones experimentales. En la primera sección, se evaluó la relación existente entre la dosificación de ozono ( 5 concentraciones) con el ozono residual en la desinfección de agua envasada.

Para ello se utilizó un diseño experimental de un solo factor, considerándose 5 niveles correspondientes a las concentraciones de ozono dosificado $(0,08 \mathrm{mg} / \mathrm{L} ; 0,10 \mathrm{mg} / \mathrm{L} ; 0,13$ $\mathrm{mg} / \mathrm{L} ; 0,15 \mathrm{mg} / \mathrm{L}$ y $0,17 \mathrm{mg} / \mathrm{L}$ ) y el ozono residual como factores de estudio.

Para la segunda parte de este estudio, enfocándose al análisis sensorial, se utilizó el diseño experimental de bloques completamente aleatorizado considerándose a un testigo, con $\mathrm{t}($ tratamientos $)=6, \mathrm{~K}$ (tratamientos a evaluarse por los catadores $)=3, \mathrm{~b}$ (catadores) $=20, \mathrm{r}$ (catadores por muestra) $=10, \lambda$ (repeticiones) $=4$, según lo descrito por Cochran (1978).

\section{Análisis Estadístico.}


Los resultados obtenidos se muestran con un análisis de varianza (ANOVA) de acuerdo a los experimentos realizados. Además de ello, se realizaron pruebas de comparación múltiple a través del test de Tuckey y Duncan.

Es importante puntualizar que se consideraron diferencias significativas a partir del 95\% de confianza. Para el análisis estadístico se emplearon los programas Infostat Version 2016 y EXCEL ${ }^{\circledR}$

\section{Resultados.}

\section{Dosificación de Ozono (O3) para agua envasada}

\section{Concentración de Ozono}

El generador de ozono presenta una escala de dosificación en unidades de Gramos/ Hora $(\mathrm{g} / \mathrm{h})$, sin embargo, estas últimas no son unidades representativas de concentración. Es por ello que surgió la necesidad de transformar las unidades iniciales en unidades de concentración, tomándose como variables principales al tiempo de dosificado, a la escala del regulador de dosificación de ozono y a la capacidad del tanque reservorio; de acuerdo a estas consideraciones se logró obtener las unidades de concentración requeridas: Miligramos de Ozono/Litro (mg O3/L) (Tabla 1).

Tabla 1. Concentraciones de Ozono para Agua Envasada

\begin{tabular}{cc}
\hline $\begin{array}{c}\text { Escala de Dosificación } \\
(\mathbf{g} / \mathbf{h})\end{array}$ & $\begin{array}{c}\text { Concentración de Ozono } \\
\left(\mathbf{m g O}_{\mathbf{3}} / \mathbf{L}\right)\end{array}$ \\
\hline $\mathbf{1 , 0 0}$ & 0,08 \\
$\mathbf{1 , 2 5}$ & 0,10 \\
$\mathbf{1 , 5 0}$ & 0,13 \\
$\mathbf{1 , 7 5}$ & $\mathbf{0 , 1 5}$ \\
$\mathbf{2 , 0 0}$ & 0,17 \\
\hline
\end{tabular}

Elaborado por: Gavilanes J. (2017)

Cálculo Demostrativo: Concentración de Ozono para una Escala de Dosificación de 1,75 $g / h$

Para este cálculo, se requiere de ciertos datos como se detalla a continuación:

- Escala de Dosificación: 1,75 g/h

- Tiempo de Dosificación: 10 min

- Capacidad Tanque Reservorio: $2000 \mathrm{~L}$ 


$$
\begin{aligned}
& 1,75 \mathrm{~g}-60 \mathrm{~min} \\
& \boldsymbol{X} \quad-10 \mathrm{~min} \\
& X=\frac{10 \min * 1,75 g}{60 \min } \\
& X=0,2916667 \mathrm{~g} \\
& X=291,6667 \mathrm{mg} \\
& {[\boldsymbol{O O 3}]=\frac{291,6667 \mathrm{mg}}{2000 \mathrm{~L}}} \\
& {[\text { Ozono }]=0,15 \mathrm{mg} / \mathrm{L}}
\end{aligned}
$$

\section{Concentración de Ozono Residual en el Agua Envasada}

La concentración de ozono residual en el agua envasada marca un parámetro importante en esta investigación. En la Tabla 2 se demuestra cuantitativamente las concentraciones de ozono residual en función a la dosificación inicial de ozono.

Tabla 2. Concentraciones de Ozono Residual para Agua Envasada.

\begin{tabular}{ccc}
\hline $\begin{array}{c}\text { Escala de } \\
\text { Dosificación } \\
(\mathbf{g} / \mathbf{h})\end{array}$ & $\begin{array}{c}\text { Concentración } \\
\text { de Ozono } \\
\left(\mathbf{m g O}_{\mathbf{3}} / \mathbf{L}\right)\end{array}$ & $\begin{array}{c}\text { Concentración de } \\
\text { Ozono Residual } \\
\left(\mathbf{m g O}_{3 \mathrm{R}} / \mathbf{L}\right)\end{array}$ \\
\hline $\mathbf{1 , 0 0}$ & 0,08 & 0,02 \\
$\mathbf{1 , 2 5}$ & 0,10 & 0,04 \\
$\mathbf{1 , 5 0}$ & 0,13 & 0,06 \\
$\mathbf{1 , 7 5}$ & $\mathbf{0 , 1 5}$ & $\mathbf{0 , 0 8}$ \\
$\mathbf{2 , 0 0}$ & 0,17 & 0,10 \\
\hline
\end{tabular}

Elaborado por: Gavilanes J. (2017).

En función a los resultados de la Tabla 2, se puede apreciar que a medida que la dosificación de ozono incrementa, el residual alcanzado también lo hace, deduciéndose que existe una relación directamente proporcional entre concentraciones.

Es así que el ozono residual $\left(\mathrm{O}_{3 \mathrm{R}}\right)$ indica la concentración que requiere el agua envasada luego de su proceso de desinfección, para mantener intacta la carga microbiana con el objetivo que posteriormente no se regeneren microorganismos que puedan alterar la calidad del agua. 


\section{Demanda de Ozono para Agua Envasada}

La demanda de Ozono indica la concentración requerida de este gas para desinfectar en su máximo potencial al agua a ser envasada, además de englobar las características fisicoquímicas y microbiológicas propias del agua. La Tabla 3 demuestra cuantitativamente la concentración equivalente a la demanda de ozono por cada dosificación aplicada al agua embotellada.

\section{Cálculo Demostrativo: Demanda de Ozono para una Concentración de 0,15 mgO3/L}

Para este cálculo, se requiere de los datos que se detallan a continuación:

- $\quad$ Concentración de Ozono: 0,15 mg/L

- $\quad$ Concentración de Ozono Residual: 0,08 mg/L

$$
\begin{gathered}
{\left[\begin{array}{ll}
\text { D O3 }
\end{array}\right]=\left[\begin{array}{l}
\text { O3 }
\end{array}\right]-\left[\begin{array}{ll}
\text { O3 } & R
\end{array}\right]} \\
{[D \text { O3 }]=0,15 \mathrm{mg} / \mathrm{L}-0,08 \mathrm{mg} / \mathrm{L}} \\
{[\text { Demanda de Ozono }]=\mathbf{0 , 0 7} \mathbf{~ m g / L}}
\end{gathered}
$$

Tabla 3. Demanda de Ozono para Agua Envasada.

\begin{tabular}{ccc}
\hline $\begin{array}{c}\text { Concentración } \\
\text { de Ozono } \\
(\mathbf{m g O} / \mathbf{L})\end{array}$ & $\begin{array}{c}\text { Concentración de } \\
\text { Ozono Residual } \\
\left(\mathbf{m g O}_{3 \mathbf{R}} / \mathbf{L}\right)\end{array}$ & $\begin{array}{c}\text { Demanda } \\
\text { de Ozono } \\
(\mathbf{m g} / \mathbf{L})\end{array}$ \\
\hline $\mathbf{0 , 0 8}$ & 0,02 & 0,06 \\
$\mathbf{0 , 1 0}$ & 0,04 & 0,06 \\
$\mathbf{0 , 1 3}$ & 0,06 & 0,07 \\
0,15 & $\mathbf{0 , 0 8}$ & $\mathbf{0 , 0 7}$ \\
$\mathbf{0 , 1 7}$ & 0,10 & 0,07 \\
\hline
\end{tabular}

Elaborado por: Gavilanes J. (2017)

De acuerdo a los resultados de la demanda de ozono, se puede observar dos concentraciones preponderantes, $0,06 \mathrm{mg} / \mathrm{L}$ y $0,07 \mathrm{mg} / \mathrm{L}$.

Es importante mencionar que estos resultados dependen de la procedencia y calidad del agua a tratar, ya que al tener un agua con mayor carga microbiana la demanda de ozono incrementará relativamente y por ende la concentración del desinfectante será mayor. 


\section{Análisis Fisicoquímico del Agua Envasada.}

La norma NTE INEN 2 200:2008 establece seis parámetros fisicoquímicos para el análisis de agua envasada, requiriendo: color, turbiedad, solidos totales disueltos (STD), $\mathrm{pH}$, cloro libre residual y dureza (Tabla 4).

Con respecto a las dosificaciones de ozono suministradas en el agua envasada, se generaron resultados positivos y dentro de los rangos establecidos por la norma.

Tabla 4. Análisis Fisicoquímico del Agua Envasada a 0,15 $\mathrm{mgO}_{3} / \mathrm{L}$

\begin{tabular}{cccccccc}
\hline Día & $\begin{array}{c}\text { REP } \\
\#\end{array}$ & Color & $\begin{array}{c}\text { Turbiedad } \\
(\mathbf{N T U})\end{array}$ & $\begin{array}{c}\text { STD } \\
(\mathbf{m g} / \mathbf{L})\end{array}$ & $\mathbf{p H}$ & $\begin{array}{c}\text { Cloro Libre } \\
\text { Residual } \\
(\mathbf{m g} / \mathbf{L})\end{array}$ & $\begin{array}{c}\text { Dureza } \\
(\mathbf{m g} / \mathbf{L})\end{array}$ \\
\hline \multirow{3}{*}{ Lun } & 1 & 0 & 0,17 & 252 & 7,10 & 0 & 0 \\
& 2 & 0 & 0,18 & 250 & 7,12 & 0 & 0 \\
& 3 & 0 & 0,18 & 250 & 7,13 & 0 & 0 \\
Mié & 1 & 0 & 0,17 & 251 & 7,11 & 0 & 0 \\
& 2 & 0 & 0,17 & 251 & 7,13 & 0 & 0 \\
\multirow{4}{*}{ Vie } & 1 & 0 & 0,17 & 252 & 7,12 & 0 & 0 \\
& 2 & 0 & 0,18 & 252 & 7,14 & 0 & 0 \\
& 3 & 0 & 0,18 & 252 & 7,12 & 0 & 0 \\
\hline
\end{tabular}

Elaborado por: Gavilanes J. (2017)

El principal parámetro a considerar fue la turbiedad, ya que a medida que la concentración de ozono incrementaba la turbiedad disminuía, es decir existe una relación inversamente proporcional entre estos factores.

Con respecto al pH existió variabilidad entre mediciones para cada dosificación de ozono, a pesar de ello se consideró la disminución del $\mathrm{pH}$ a partir de la dosificación de $0,15 \mathrm{mg} / \mathrm{L}$. Por otro lado, los resultados de los sólidos totales disueltos (STD) se mantuvieron constantes para las concentraciones de ozono aplicadas.

Finalmente, es importante mencionar que tanto los parámetros de color, dureza y cloro libre residual mantuvieron un resultado equivalente a cero, lo cual garantiza la calidad del agua ozonizada y los rangos establecidos en la norma NTE INEN 2 200:2008. Para respaldar los resultados experimentales, se enviaron las muestras al Laboratorio Acreditado de Control de Calidad de la EP- EMAPA-A 


\section{Análisis Microbiológico del Agua Envasada.}

De igual manera, la norma NTE INEN 2 200:2008 establece tres requisitos microbiológicos: aerobios mesófilos, coliformes totales y coliformes fecales (Tabla 5).

De acuerdo a las concentraciones de ozono utilizadas para desinfectar el agua envasada considerando los parámetros microbiológicos marcados en la norma, todos fueron cumplidos satisfactoriamente y con resultados equivalentes a cero según lo estipulado por la norma.

Tabla 5. Análisis Microbiológico del Agua Envasada a $0,15 \mathrm{mg} \mathrm{O}_{3} / \mathrm{L}$

\begin{tabular}{ccccc}
\hline Día & $\begin{array}{c}\text { REP } \\
\#\end{array}$ & $\begin{array}{c}\text { Aerobios } \\
\text { Mesófilos }\end{array}$ & $\begin{array}{c}\text { Coliformes } \\
\text { Totales }\end{array}$ & $\begin{array}{c}\text { Coliformes } \\
\text { Fecales }\end{array}$ \\
\hline \multirow{3}{*}{ Lun } & 1 & 0 & 0 & 0 \\
& 2 & 0 & 0 & 0 \\
\multirow{4}{*}{ Mié } & 3 & 0 & 0 & 0 \\
& 1 & 0 & 0 & 0 \\
& 2 & 0 & 0 & 0 \\
Vie & 3 & 0 & 0 & 0 \\
& 1 & 0 & 0 & 0 \\
& 2 & 0 & 0 & 0 \\
\hline
\end{tabular}

Elaborado por: Gavilanes J. (2017)

\section{Análisis Sensorial del Agua Envasada.}

El objetivo del análisis sensorial fue seleccionar entre las cinco concentraciones de ozono, la dosificación óptima escogida por los consumidores, considerándose el Olor y Sabor característico que el proceso de ozonización genera en el agua posteriormente a su tratamiento de desinfección y, además analizando el parámetro de Aceptabilidad que engloba a todos los requisitos de esta investigación.

Tabla 6. Resultados de la Catación de Agua Envasada a diferentes Concentraciones de

Ozono.

\begin{tabular}{cccc}
\hline$\left[\right.$ Ozono] $\left(\mathbf{m g O}_{3} / \mathbf{L}\right)$ & Olor & Sabor & Aceptabilidad \\
\hline $\mathbf{0 , 0 8}$ & Inobjetable & Inobjetable & No Aceptaría \\
$\mathbf{0 , 1 0}$ & Inobjetable & Inobjetable & No Aceptaría \\
$\mathbf{0 , 1 3}$ & Inobjetable & Inobjetable & No Aceptaría \\
0,15 & Inobjetable & Inobjetable & Aceptaría \\
$\mathbf{0 , 1 7}$ & Inobjetable & Inobjetable & Quizá Aceptaría \\
\hline
\end{tabular}

Elaborado por: Gavilanes J. (2017) 
En la Tabla 6 se observa que, en función al análisis sensorial, tanto para los parámetros de Olor y Sabor, los consumidores no encontraron presencia de los mismos considerando las cinco concentraciones de ozono utilizadas, marcando estos parámetros como Inobjetable.

Figura 1. Concentración de Ozono VS Aceptabilidad mediante el paquete estadístico Infostat

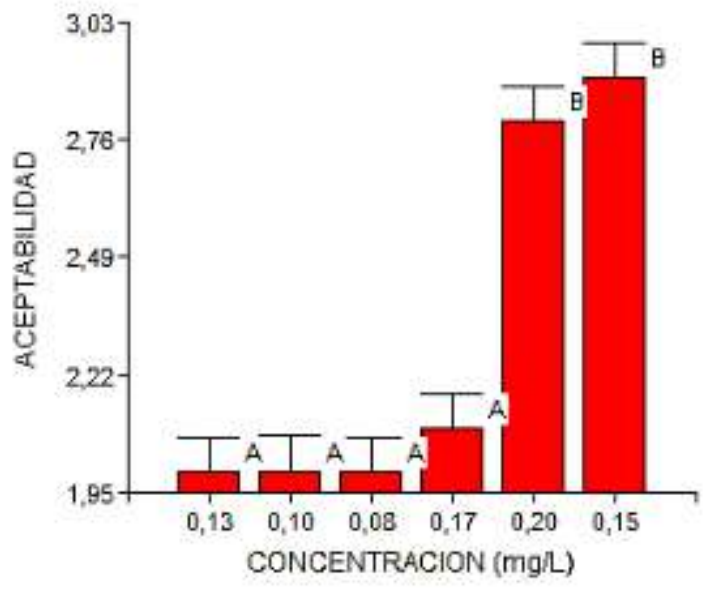

En la Figura 1, se encuentra la relación de Aceptabilidad en función a las dosificaciones de ozono, además de un testigo utilizado para este análisis sensorial. Se marcó con la dosificación de 0,20 $\mathrm{mgO} 3 / \mathrm{L}$ al testigo, que en este caso fue el "Agua Cielo", considerando que el fundamento de desinfección de su agua embotellada es similar al aplicado por la Envasadora de Agua de la EP-EMAPA-A.

\section{Discusión.}

Con respecto a lo anteriormente mencionado, se observa una considerable aceptación por parte de los consumidores para el agua envasada a una concentración de 0,15 mg O3/L, además de la similitud con el testigo, considerándose que es una marca comercial reconocida a nivel nacional lo cual la hace competitiva.

Por otro lado, las concentraciones de 0,08; 0,10 y 0,13 mg O3/L, no marcan aceptación debido a que durante la filtración del agua se pierden minerales y a una concentración más baja de ozono resulta desagradable para el paladar del consumidor.

Sin embargo, a concentraciones más elevadas como la dosificación de 0,17 mg O3/L resulta de cierta manera aceptable a pesar de su bajo porcentaje, según el análisis sensorial realizado a los consumidores. 
Es de esta manera que la escala de $1,75 \mathrm{~g} / \mathrm{h}$ correspondiente a una concentración de $0,15 \mathrm{mg}$ O3/L fue seleccionada como la dosificación óptima, misma que cumple con los parámetros fisicoquímicos y microbiológicos que establece la norma NTE INEN 2 200:2008 para agua envasada y respaldada en los resultados del análisis.

\section{Conclusiones.}

- Se evaluó la dosis óptima de Ozono (O3) para la desinfección de agua embotellada producida en la planta de tratamiento de agua envasada de la EP-EMAPA-A, obteniéndose resultados positivos para la dosificación de $0,15 \mathrm{mg}$ O3/L (Escala de dosificación: 1,75 g/h; Ozono Residual: 0,08 mg/L; Demanda de Ozono: 0,07 mg/L), respaldándose en las pruebas fisicoquímicas y microbiológicas llevadas a cabo para el cumplimiento de los rangos establecidos en la norma NTE INEN 2 200:2008, además de un análisis sensorial que marca un precedente en cuanto a la aceptabilidad por parte de los consumidores.

\section{Referencias Bibliográficas.}

American Public Health Association, American Water Works Association, Water and Environment Federation. (1999). Standard Methods for the Examination of Water and Wastewater. Recuperado de: www.mwa.co.th/download/file_upload/SMWW_4000-6000.pdf

Beltrán de Heredia, J., Torregrosa-Antón, J., García- Rodríguez, J. (2002). Proceso combinado de digestión anaerobia y ozonización para la depuración de aguas residuales de alta carga orgánica Alimentación Equipos y Tecnología. 21(169):71-77.

Chávez, G., Almagor, L. \& Chalan, D. (2013). Propuesta estratégica y estudio de pre factibilidad para la creación de una empresa dedicada a la producción y venta de botellones de agua purificada. Universidad Central del Ecuador, Quito.

CHEMETRICS, INC. (2015). The Measurement of Dissolved Ozone. Recuperado de: https://www.chemetrics.com/image/data/product/pdf/Measurement_of_Ozone_White_Paper _Final.pdf

Deininger, R., Skadsen, J., Sanford, L. \& Myers, A. (1998). El Agua Potable: Desinfección del Agua con Ozono. Simposio Regional sobre la Calidad del Agua: Desinfección Efectiva. Lima.

De la Fuente, A. (2013, 05 de febrero). Una década de cambios en el mercado. Revista Lideres. Ec. Recuperado de: http://www.revistalideres.ec/lideres/decada-cambiosmercado.html 
Galvin, MR. (Sin fecha.). Ensayos con Ozono: Análisis de Aguas y Ensayos de Tratamiento. Recuperado de: http://www.elaguapotable.com/Ensayos\%20con\%20Ozono\%20_R.pdf

HACH Company. (2015). Ozono: Método Índigo. Recuperado de: http://es.hach.com/

HACH Company. (2000). Manual de Análisis de Agua. Segunda Edición en Español. Recuperado de: www.hach.com/asset-get.download.jsa?id=7639984469

HIDRITEC. (2014). Desinfección con Ozono. Recuperado de: http://www.hidritec.com/hidritec/desinfeccion-con-ozono

Instituto Ecuatoriano de Normalización (INEN). (2014). Norma Técnica Ecuatoriana: Agua Potable. Requisitos. Primera Edición. Recuperado de: http://normaspdf.inen.gob.ec/pdf/nte/1108-5.pdf

Instituto Ecuatoriano de Normalización (INEN). (2008). Norma Técnica Ecuatoriana: Agua Purificada Envasada. Requisitos. Primera Edición. Recuperado de: http://normaspdf.inen.gob.ec/pdf/nte/2200.pdf

Khadre, M.; Yousef, A.; Kim, J. (2001). Microbiological Aspects of Ozone Applications in Food. Journal of Food Science. Institute of Food Technologist. Washington, D. C.- Estados Unidos de America. Pp: 1242-1252

Kolosov, P., Peyot, M. L. y Yargeau, V. (2018). Novel materials for catalytic ozonation of wastewater for disinfection and removal of micropollutants. Science of the Total Environment, 644, 1207-1218. doi: 10.1016/j.scitotenv.2018.07.022

Martínez, E. (2016). Ozono: Antecedentes. Capítulo 2. Recuperado de: http://catarina.udlap.mx/u_dl_a/tales/documentos/lim/martinez_e_fl/capitulo2.pdf

Montgomery D. (2008). Diseño y Análisis de Experimentos. Segunda Edición. Editorial Limusa S.A. DF- México. Pp: 163- 165.

Red Madrileña de Tratamientos Avanzados para Aguas Residuales con Contaminantes no Biodegradables (REMTAVARES). (2008). Aplicación de la Ozonización en el Tratamiento de Aguas: Descripción y Funcionamiento. Recuperado de: http://www.madrimasd.org/blogs/remtavares/2008/01/16/82477

Rodríguez, J. (2003). El Ozono y la Desinfección del Agua. Recuperado de: http://www.consumer.es/seguridad-alimentaria/ciencia-y tecnología/ 2003/05/27/ 6613.php.

Saltos, H. (2010). Sensometría: Análisis en el Desarrollo de Alimentos Procesados. Primera Edición. Editorial Pedagógica Freire. Riobamba- Ecuador. 
Singh, N., Singh, R., Bhunia, A., Stroshine, R. (2002). Efficacy of chlorine dioxide, ozone, and thyme essential oil or a sequential washing in killing Escherichia coli O157:H7 on lettuce and baby carrots. Food Science \& Technology-Lebensmittel-Wissenschaft \& Technologie. 35:720-729.

Skadsen, J., Sanford, L., Myers, A. \& Deininger, R. (Sin fecha). Ozono. Universidad de Michigan, Estados Unidos.

Vargas, L. (2004). Tratamiento de Agua para Consumo Humano: Plantas de Filtración Rápida.Manual I: Teoría. Tomo I: Capitulo 10: Desinfección. Lima- Perú. Pp: 153- 160.

Wei, C., Zhang, F., Hu, Y., Feng, C. y Wu, H. (2017). Ozonation in water treatment: The generation, basic properties of ozone and its practical application. Reviews in Chemical Engineering, 33(1), 49-89. doi: 10.1515/revce-2016-0008 


\section{Para citar el artículo indexado.}

Córdova M, Gavilanes J, Ruíz O. \& Vega J. (2018). Desarrollo del proceso de ozonización en la planta de tratamiento de agua envasada de la empresa pública-empresa municipal de agua potable y alcantarillado de Ambato (EP-EMAPA-A). Revista electrónica Ciencia Digital 2(3), 1-14. Recuperado desde: http://www.cienciadigital.org/revistascienciadigital/index.php/CienciaDigital/article/view/70 $\underline{165}$

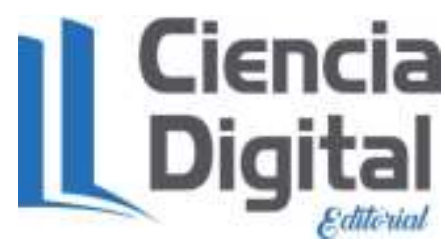

El artículo que se publica es de exclusiva responsabilidad de los autores y no necesariamente reflejan el pensamiento de la Revista Ciencia Digital.

El articulo queda en propiedad de la revista y, por tanto, su publicación parcial y/o total en otro medio tiene que ser autorizado por el director de la Revista Ciencia Digital.
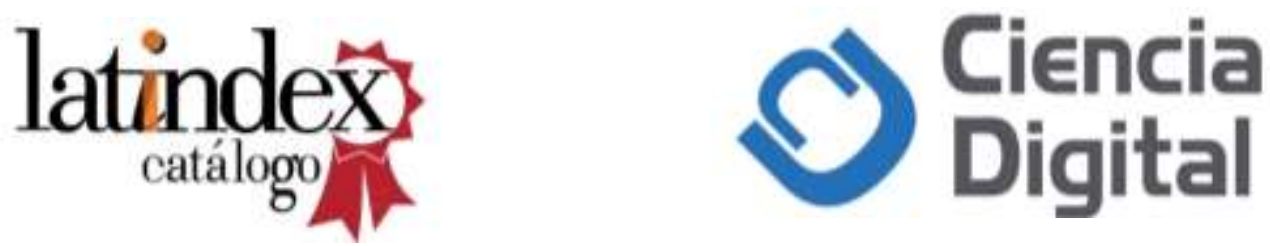